\title{
PENGUKURAN TINGGI DAN DIAMETER TANAMAN MERANTI MERAH (Shorea pauciflora C.F. Gaertn) DI KEBUN RAYA UNMUL SAMARINDA (KRUS)
}

\section{HEIGHT AND DIAMETER MEASUREMENT OF RED MERANTI PLANT (Shorea pauciflora C.F. Gaertn) IN KEBUN RAYA UNMUL SAMARINDA (KRUS)}

\author{
Herijanto Thamrin* \\ Politeknik Pertanian Negeri Samarinda, Kampus Gunung Panjang, Jl. Samratulangi, \\ Samarinda, Indonesia \\ herijantothamrin@gmail.com
}

\begin{abstract}
Forest is a natural resource that can be renewed and utilized. Utilization of forest resources must pay attention to the principle of being beneficial and providing sustainable results for humans. Forests must be maintained in order to get these benefits.

The purpose of this study was to determine the height and diameter of the Red Meranti tree (Shorea pauciflora C.F. Gaertn) at the age of 13 at the Botanical Garden Unmul Samarinda (KRUS). The expected results of this study are to provide information on the height and diameter growth of red meranti (Shorea pauciflora.C.F.Gaertn).

This research was conducted at the Kebun Raya Unmul Samarinda (KRUS) for 2 months, namely July - August 2020. Sampling was done with simple random sampling, on red meranti plants 13 years old with a spacing of $6 \times 6 \mathrm{~m}$ as much as 50 trees. Measuring Diameter using Phiband and Height using a clinometer and a $4 \mathrm{~m}$ long pole tool. The results obtained were processed with simple statistics and analyzed using descriptive methods.

Based on the results of the processing and data analysis carried out, it can be concluded that the diameter growth of the red meranti plant aged 13 years in the Botanical Garden of Unmul Samarinda (KRUS) did not vary (relatively uniform) with an average diameter of $13.42 \mathrm{~cm}$, where the plant with a diameter large grow on the edge of the area and small ones are in the middle of the area. Meanwhile, the height growth of red meranti plants did not show any variation (relatively uniform) with an average height of $11.59 \mathrm{~m}$. To get optimal results, both in height and diameter, plant maintenance activities are needed, especially cleaning existing weeds.
\end{abstract}

Keywords: diameter, height, red meranti

\section{PENDAHULUAN}

Hutan merupakan salah satu sumber daya alam yang dapat diperbaharui dan dimanfaatkan. Pemanfaatan sumber daya hutan yang haruslah memperhatikan asas bermanfaat dan memberikan hasil terusmenerus bagi manusia (Wirakusuma, 1980). Hutan wajib dijaga keberadaannya agar bisa memberi manfaat tersebut.

Hutan sebagai asosiasi masyarakat tumbuhan dengan dominasi pohon-pohon yang selalu mengalami perubahan setiap waktu. Oleh karena itu jumlah kekayaan yang terkandung didalam hutan juga selalu berubah. Hal ini menyebabkan inventore hutan tidak mudah dilaksanakan.

Pengukuran merupakan hal yang paling penting dilakukan, karena dapat mengetahui atau menduga potensi suatu tegakan ataupun suatu komunitas tertentu. Dalam memperoleh data pengukuran, jenis dan cara penggunaan alat merupakan faktor penentu utama yang mempengaruhi ketelitian data yang diperoleh. Semakin baik alat yang dipergunakan maka semakin baik pula hasil pengukuran yang akan didapat. Demikian pula halnya dengan kemampuan pengamatan dalam pengukuran, semakin baik dalam penggunaan suatu alat maka semakin baik 
pula data yang dikumpulkan (Anonim, 2013).

Pendugaan suatu komunitas salah satunya dilakukan dengan melakukan pengukuran pada tinggi dan diameter pohon dari komunitas yang akan diketahui tersebut. Tinggi dan diameter pohon merupakan dimensi pohon yang sangat penting dalam pendugaan potensi pohon dan tegakan. Data tinggi dan diameter bukan hanya diperlukan untuk menghitung nilai luas bidang dasar suatu tegakan melainkan juga dapat digunakan untuk menentukan volume pohon dan tegakan, berguna dalam pengaturan penebangan dengan batas tinggi dan diameter tertentu serta dapat digunakan untuk mengetahui struktur suatu tegakan hutan.

Tujuan dari penelitian ini adalah untuk mengetahui tinggi dan diameter pohon meranti merah (Shorea pauciflora C.F.Gaertn) yang berumur 13 tahun di Kebun Raya Unmul Samarinda (KRUS). Hasil yang diharapkan dari penelitian ini adalah agar dapat memberikan informasi pertumbuhan tinggi dan diameter tanaman meranti merah (Shorea pauciflora C.F.Gaertn).di lokasi tersebut dan sebagai bahan masukan untuk pengembangan jenis ini khususnya di Kalimantan Timur.

\section{METODOLOGI}

\section{Lokasi dan Waktu Penelitian}

Penelitian ini dilaksanakan di Kebun Raya Unmul (KRUS)Samarinda. Waktu yang direncanakan dalam penelitian selama 2 (dua) bulan yaitu pada bulan Juli - Agustus 2019, yang meliputi studi literatur, persiapan penelitian, pengumpulan data dan pengolahan data.

\section{Alat dan Bahan}

a. Uji Regresi adalah:

Alat digunakan dalam penelitian ini

a. Alat tulis menulis

b. Clinometer,

c. Phiband,

d. Parang,

e. Galah sepanjang 4 meter, digunakan sebagai alat bantu pengukuran tinggi pohon. f. Kamera.

g. Label, digunakan untuk penomoran pohon.

b. Bahan

Bahan yang digunakan dalam penelitian ini adalah tanaman meranti merah (Shorea pauciflora C.F.Gaertn) yang berumur 13 tahun dengan jarak tanam $6 \mathrm{~m} \times 6 \mathrm{~m}$ sebanyak 50 pohon.

\section{Prosedur Penelitian}

Adapun prosedur penelitian ini sebagai berikut:

1. Persiapan alat yang akan dibawa ke lapangan.

2. Pemberian label pada pohon yang akan diukur

3. Pengukuran diameter, pengukuran diameter pohon yaitu diukur setinggi dada atau pada ketinggian 1,3 meter di atas permukaan tanah dengan menggunakan alat phiband.

4. Pengukuran tinggi, pengukuran tinggi menggunakan clinometer dan bantuan galah (pole) setinggi 4 meter.

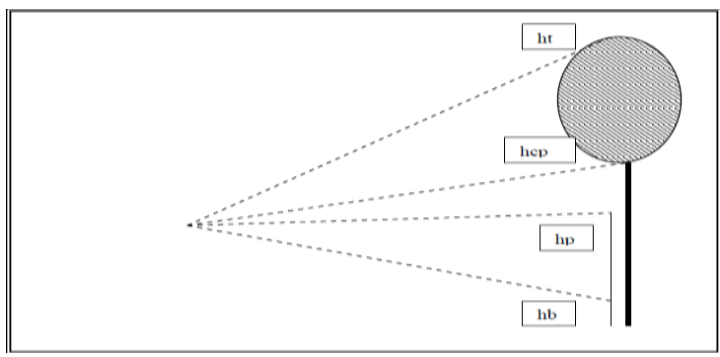

Gambar 1. Pengukuran Tinggi Pohon dengan Clinometer dan Alat Bantu Galah

\section{Pengolahan Data}

Untuk menghitung tinggi pohon digunakan rumus sebagai berikut (Anonim 1999):

$$
\mathrm{H}=\left\{\frac{\% \mathrm{ht}-\% \mathrm{hb}}{\% \mathrm{hp}-\% \mathrm{hb}}\right\} x \text { panjang galah }
$$

Keterangan :

$\mathrm{H} \quad=$ Tinggi total hasil pengukuran

$\%$ ht $=\%$ pembidikan ke puncak pohon

$\%$ hp $=\%$ pembidikan ke ujung galah

$\% \mathrm{hb}=\%$ pembidikan ke pangkal pohon

Untuk menghitung rata-rata nilai tinggi dan diameter digunakan rumus: 


$$
\overline{\mathrm{x}}=\frac{\sum \mathrm{x}}{\mathrm{n}}
$$

Keterangan:

$$
\begin{array}{ll}
\bar{x} & =\text { nilai rata-rata } \\
\sum X & =\text { jumlah nilai individu parameter } \\
& \text { (tinggi/ diameter) } \\
\mathrm{n} & =\text { jumlah individu pengamatan }
\end{array}
$$

Untuk menghitung standar deviasi menggunakan rumus:

$$
S d=\sqrt{\frac{\sum x^{2}-\frac{\left(\sum x\right)^{2}}{n}}{n-1}}
$$

Keterangan :

$$
\begin{array}{ll}
\mathrm{Sd} & =\text { Standar Deviasi } \\
\mathrm{X} & =\text { nilai (tinggi, diameter) } \\
\mathrm{n} & =\text { Jumlah Pohon }
\end{array}
$$

Kemudian untuk mengetahui dispersi relatif yang dikenal dengan koefisien variasi (coffecien of variation) dengan rumus sebagai berikut (Nugroho, 1998):

$$
\mathrm{CV}=\frac{\mathrm{Sd}}{\overline{\mathrm{x}}} \mathrm{x} 100 \%
$$

Keterangan:

$$
\begin{array}{ll}
\mathrm{CV} & =\text { Koefisien Variasi } \\
\mathrm{Sd} & =\text { Standar deviasi } \\
\bar{x} & =\text { Rata-Rata (diameter/tinggi) }
\end{array}
$$

Adapun kriteria dari koefisien

variasi adalah

$$
\begin{array}{ll}
\text { CV } & =1-10 \% \text { (kecil) } \\
\text { CV } & =10-20 \% \text { (sedang) } \\
\text { CV } & =20-30 \% \text { (besar) } \\
\text { CV } & =>30 \% \text { (sangat besar) }
\end{array}
$$

\section{Analisis Data}

Hasil pengolahan data dianalisis dengan menggunakan metode deskriptif, yaitu suatu metode yang digunakan untuk menemukan pengetahuan yang seluasluasnya terhadap objek penelitian pada kurun waktu tertentu atau mengumpulkan informasi mengenai status variabel atau tema,gejala atau keadaan yang ada, yaitu keadaan gejala menurut apa adanya pada saat penelitian dilakukan (Nugroho, 1998). Data yang bersifat kualitatif dianalisis secara deskriptif kualitatif dan data-data yang bersifat kuantitatif dianalisis secara deskriptif kuantitatif.

\section{HASIL DAN PEMBAHASAN}

\section{Hasil}

Tabel 1. Data Hasil Pengukuran tinggi dan diameter Tanaman Meranti Merah (Shorea pauciflora C.F.Gaertn) umur 13 tahun sebanyak 50 pohon.

\begin{tabular}{|c|c|c|c|c|c|}
\hline No & Variabel & $\mathrm{N}$ & $\begin{array}{c}\text { Rata- } \\
\text { rata }\end{array}$ & $\mathrm{Sd}$ & $\mathrm{Cv}$ \\
\hline 1. & Tinggi & 50 & 11,59 & 0,27 & 2,31 \\
\hline 2. & Diameter & 50 & 13,42 & 0,33 & 2,45 \\
\hline
\end{tabular}

\section{Pembahasan}

Dari hasil pengukuran dan pengolahan data didapatkan rata-rata diameter sebesar $13,42 \mathrm{~cm}$ dengan simpangan baku $0,33 \mathrm{~cm}$ dengan koefisien variasi sebesar 2,45 \%. Nilai koefisien variasi termasuk kategori kecil, artinya tingkat pertumbuhannya relatif sama.. Dengan pertumbuhan tinggi dimana menunjukkan hasil pertumbuhan yang seragam dengan rata-rata pertumbuhan tinggi sebesar 11,59 meter dengan simpangan baku sebesar 0,27 dan koefisien variasi sebesar 2,31 \%. Nilai koefisien variasi adalah kecil, artinya tingkat pertumbuhannya relatif seragam. Bila dilihat kondisi lapangan, selain tanaman pokok banyak pula tumbuh tanaman lain yang lebih besar (gulma) sehingga pada saat penelitian terlihat tanaman pokok relatif tertekan hidupnya karena rata-rata tajuknya berada di bawah tanam lain (gulma). Hal ini mengindikasikan bahwa tidak pernah dilakukan perawatan yang memadai. Marjenah (2001) menyatakan bahwa salah satu faktor penentu pertumbuhan diameter yang ideal adalah jarak tanam. Pertumbuhan diameter lebih cepat pada tempat terbuka dari pada tempat ternaung, dapat dilihat pada sehingga tanaman yang ditanam di tempat terbuka cenderung pendek dan kekar. Hal ini akan 
berpengaruh positif terhadap pertumbuhan diameter. Kemudian Bratawinata (1988) menyatakan, bahwa jarak tanam rapat memungkinkan terjadinya persaingan antara tanaman yaitu persaingan dalam memperebut ruang tumbuh (persaingan tajuk) untuk mendapatkan sinar matahari maupun persaingan dalam memperebut unsur hara dan umumnya sering terjadi pada tanaman yang cepat tumbuh. Hal ini sebenarnya berpengaruh positi terhadap pertumbuhan tinggi. Namun demikian dengan jarak tanam yang lebar, terbuka lebar pula pertumbuhan gulma yang sangat mengganggu pertumbuhan tanaman pokok. Anonim (1986) menyatakan bahwa dalam satu tanaman sering terjadi persaingan antar tanaman maupun antar tanaman dengan gulma untuk mendapatkan unsur hara, air, cahaya matahari maupun ruang tumbuh. Selain itu dengan adanya tanaman lain yang tumbuh (gulma) juga merusak secara fisik, karena ditemukan banyak tanaman pokok yang patah.

Dengan adanya pengaturan jarak tanam yang tepat, akan memungkinkan laju pertumbuhan tinggi tanaman menjadi maksimal, dalam hal pengaturan jarak tanam dimaksudkan untuk memberi ruang tumbuh bagi tanaman, kemudian dengan menghilangkan tanaman lain (gulma) akan mengurangi persaingan antara tanaman dalam mendapatkan unsur hara, air, dan cahaya matahari serta mengurangi kerapatan antar tanaman (Anonim, 2013). Dengan demikian perlu pertimbangan yang matang dalam menentukan jarak tanam yang ideal agar mampu mengurangi pertumbuhan gulma yang sangat merugikan tanaman pokok. Kemudian hal lain yang juga penting adalah perawatan tanaman.

\section{KESIMPULAN DAN SARAN}

\section{Kesimpulan}

Berdasarkan hasil pengolahan dan analisis data yang dilakukan, maka dapat disimpulkan bahwa perumbuhan diameter tanaman meranti merah umur 13 tahun di Kebun Raya Unmul Samarinda (KRUS) tidak bervariasi (relatif seragam) dengan rata-rata diameter sebesar 13,42 cm, dimana tanaman dengan diameter besar tumbuh di bagian pinggir areal dan yang kecil berada di tengah areal. Sedangkan pertumbuhan tinggi tanaman sungkai juga tidak menunjukan variasi (relatif seragam) dengan rata-rata tinggi sebesar $11,59 \mathrm{~m}$.

\section{Saran}

Untuk mendapatkan hasil yang lebih optimal baik tinggi maupun diameter diperlukan kegiatan pemeliharaan tanaman terutama membersihkan gulmagulma yang ada.

\section{DAFTAR PUSTAKA}

Anonim. 1986. Dasar Umum IImu Kehutanan Buku II. Kegiatan Dalam Bidang Kehutanan Badan Kerja Sama Perguruan Tinggi Negeri Indonesia Bagian Timur. Jakarta.

Anonim, 2013. Inventarisasi Hutan. http:// forester. Untad. Blogspot. Com/ 2013/01/ makalah-lengkapinventarisasi hutan.html.

Bratawinata. 1988. Beberapa Contoh Pohon - Pohon Tanaman Industri Cepat Tumbuh,Univerisitas Mulawarman Samarinda.

Marjenah, 2001. Pengaruh Perbedaan Naungan di Persemaian Terhadap Pertumbuhan dan Respon Morfologi Dua Jenis Semai, Meranti. Jurnal IImiah Kehutanan

Nugroho,1998. Dasar-Dasar IImu Statistik Jakarta.

Wirakusumah,S. 2003. Dasar-dasar Ekologi bagi Populasi dan Komunitas UI Press. Jakarta. 